\title{
A CRIAÇÃO DO INSTITUTO DE EDUCAÇÃ̃ NO MUNICÍPIO DE SÃO GONÇALO: TENSÕES ENTRE O PÚBLICO E O PRIVADO
}

\author{
Karyne Alves dos Santos ${ }^{i}$ \\ CETRAF/FME \\ karynealves@oi.com.br
}

\begin{abstract}
Resumo: O trabalho visa compartilhar a implantação do Curso Normal do município de São Gonçalo no Estado do Rio de Janeiro, a partir da criação do Instituto de Educação. Desenvolvi uma pesquisa qualitativa e bibliográfica, tendo como uma das fontes o primeiro impresso do município - o Jornal O SÃO GONÇALO. A relação entre memória e história foram discutidas numa perspectiva do passado sempre presente e de tempo vivido na rememoração. Utilizei também a abordagem teórica da micro-história, a decifração de pistas e o conceito de escala, com vistas a compreender a criação do Instituto de Educação, nomeado anos depois como Instituto de Educação Clélia Nanci. A pesquisa aponta os (des) caminhos que envolvem a constituição da profissão docente fluminense, a partir da escala local, mergulhados nas contradições políticas e sociais que "assombram" a educação nacional.
\end{abstract}

Palavras-chave: Curso de Formação de Professores em Nível Médio; Formação de Professor em São Gonçalo; História da Educação;

\section{LA CREACIÓN DEL INSTITUTO DE EDUCACIÓN EN EL MUNICIPIO DE SÃO GONÇALO: TENSIONES ENTRE PÚBLICO Y PRIVADO}

Resumen: Este artículo tiene como objetivo compartir la ejecución del curso normal de San Gonzalo en el Estado de Río de Janeiro, a partir de la creación del Instituto de Educación. He desarrollado una cualitativa y la literatura, y como una de las primeras fuentes impresas de la municipalidad - el diario O SON GONÇALO. La relación entre la memoria y la historia se discutieron en una perspectiva del pasado siempre está presente y el tiempo vivían en memoria. También se utiliza el enfoque teórico de la micro - historia, descifrando pistas y el concepto de escala, con el fin de entender la creación del Instituto de Educación, designado años después como un Instituto de Educación Clelia Nanci. Las investigaciones apuntan las (des) caminos que implican el establecimiento de profesión docente Río, desde el nivel local, cargados de contradicciones políticas y sociales " assobram " educación nacional.

Palabras clave: Profesor del curso de formación en el Nivel Medio; La formación del profesorado en São Gonçalo ; Historia de la Educación;

\section{A CRIAÇÃO DO INSTITUTO DE EDUCAÇÃO NO MUNICÍPIO DE SÃO GONÇALO: TENSÕES ENTRE O PÚBLICO E O PRIVADO}

A trajetória histórica da educação nacional e gonçalense têm sido tecidas pelas memórias coletivas dos diferentes sujeitos, em suas ações no presente e no passado.

Revista Interinstitucional Artes de Educar. Rio de Janeiro, V. 2 N. Especial - pag 312-326 (jun - out 2016): "Vozes da Educação" 
Reconhecer essas histórias leva-nos à condição de refletir sobre as lutas por mudanças políticas, sociais, econômicas e educacionais no município de São Gonçalo. Sabemos que, tal como o país, a cidade sofreu a imposição de práticas políticas que, no âmbito educacional, desconsideraram saberes e experiências populares.

Apesar das propostas educacionais municipais terem sido marcadas, de um lado, por interesses políticos e econômicos, e, por outro lado, atravessadas por toda a sorte de negligências de igual natureza, sabemos que houve (e há) inúmeras lutas e resistências.

Em meio às contradições, lacunas e descontinuidades que regem as políticas públicas no âmbito educacional, existem movimentos cotidianos no interior das escolas, que tentam reinventá-la. Os atores são inúmeros/as professores/as, alunos/as, gestores/as, funcionários/as e responsáveis comprometidos/as com uma educação de qualidade para todos/as.

A criação e a expansão das escolas públicas no município de São Gonçalo se deram em meio a uma rede de escolas particulares, como nos aponta Figueirêdo (2010):

A cidade de São Gonçalo não possuía, até o inicio dos anos de 1960, ginásio público, exigindo que a opção das famílias para a continuidade dos estudos de seus filhos recaísse na matricula em escolas particulares da cidade (FIGUEIRÊDO apud NUNES, 2010, p. 22).

Dentre as primeiras escolas particulares destaco o Colégio São Gonçalo, Externato Santa Terezinha, Colégio Nilo Peçanha, Colégio Nossa Senhora das Dores, Colégio Dom Hélder, Colégio Nossa Senhora da Paz e Colégio Santa Catarina.

Em meados dos anos 50, estas escolas iniciaram a oferta do Curso Normal no município de São Gonçalo, conforme anúncios publicados no Jornal “O SÃO GONÇALO”: 
Fotografia 1 - Anúncio do Colégio Santa Catarina e Colégio Nilo Peçanha

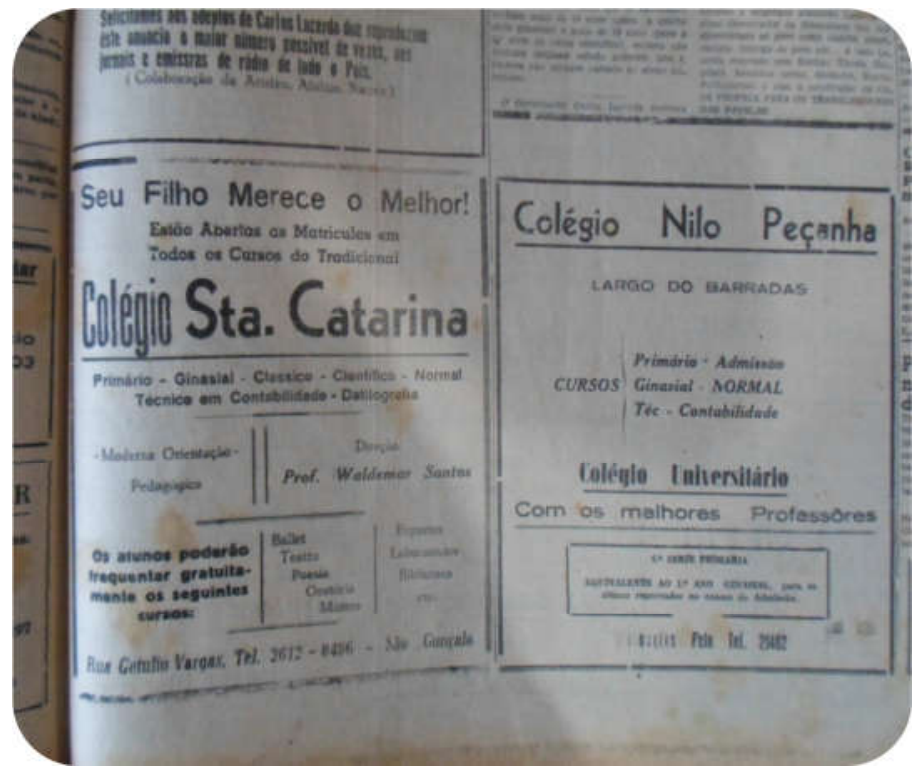

Legenda: Anúncio publicado no Jornal “O SÃO GONÇALO” - Ano: 1957 Fonte: Jornal “O SÃ̃ GONÇALO

Nas buscas realizadas nos arquivos do Jornal "O SÃO GONÇALO”, encontrei, em praticamente todos os exemplares, anúncios demonstrando a presença e divulgação das escolas particulares no campo educacional gonçalense. Entendo esta presença como fruto da ausência de investimentos públicos na educação no município de São Gonçalo.

Sobre esta questão, trago algumas reflexões: a quem interessou a expansão das escolas particulares no município de São Gonçalo? A que clientela estas escolas atendiam? Onde estariam os/as alunos/as cujas famílias não tinham condições financeiras de pagar seus estudos?

De acordo com Figueirêdo (2004), a preocupação com a formação de professores em São Gonçalo foi mais intensa na gestão do Prefeito Gilberto Afonso Pires (1951-1955), pois este "empreendeu esforços no sentido de conquistar um Instituto de Educação, que pudesse contribuir para uma instrução primária municipal mais eficiente e ao alcance da maioria" (FIGUEIRÊDO, 2004, p. 104).

No entanto, o Instituto de Educação não foi criado na década de 50. A luta por uma “instituição pública de ensino médio, responsável pela formação de professores somente se concretizou em São Gonçalo na década de 60" (FIGUEIRÊDO, 2004, p. 104).

No âmbito legal, o Instituto de Educação de São Gonçalo foi criado a partir da "Lei 4.906 de 20 de novembro de 1961, porém sua autorização de funcionamento foi concedida no Diário Oficial de 30 de janeiro de 1963" (SALLY, 2006, p. 62).

Seu funcionamento não foi imediato, contando com a influência de políticos do 
município junto ao Governo Estadual e a mobilização popular, conforme reportagem abaixo, publicada na primeira página do Jornal "O SÃO GONÇALO” na edição de 19 de janeiro de 1963.

Fotografia 2 - Reportagem sobre funcionamento do Curso Normal

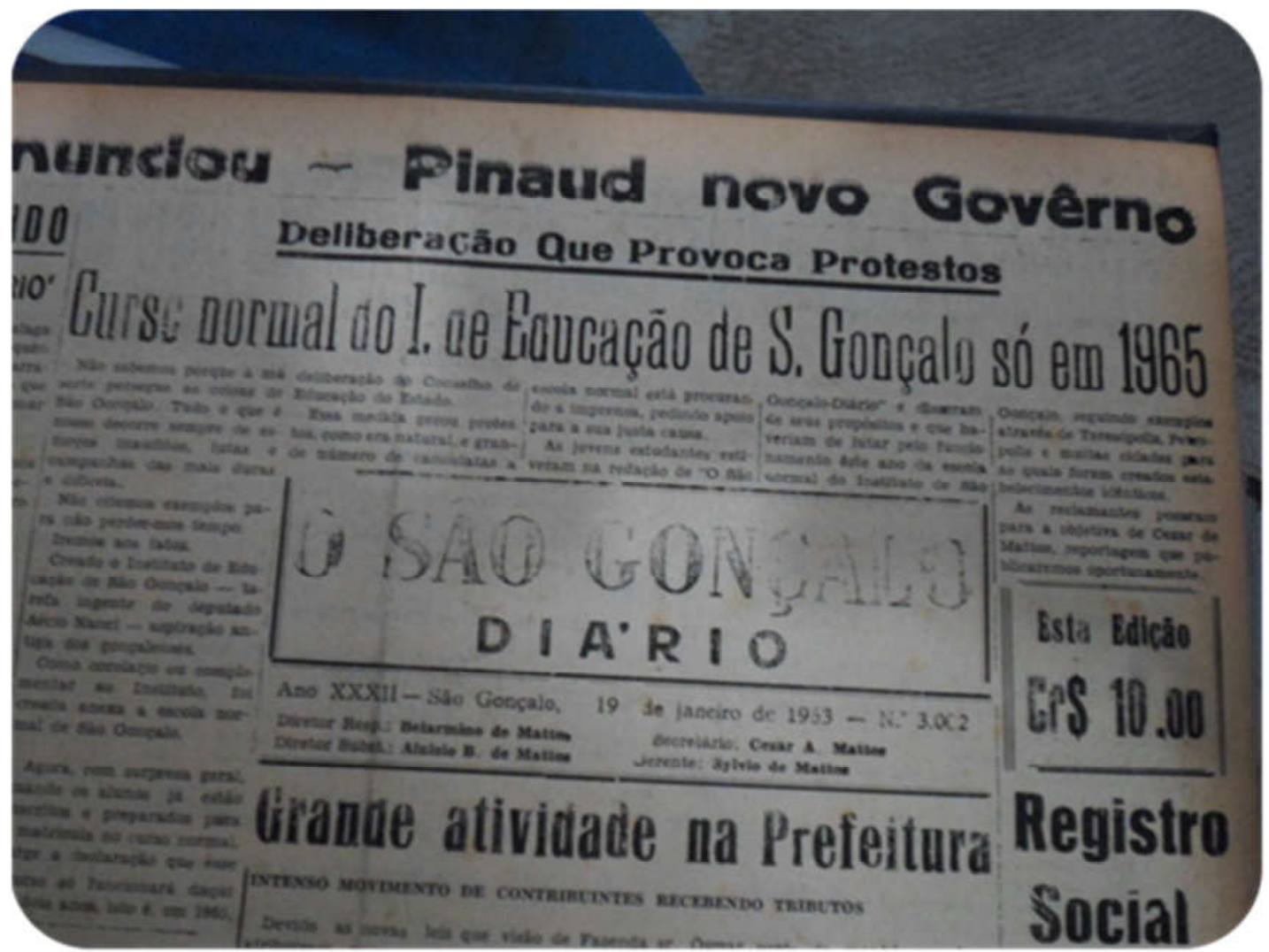

Legenda: Reportagem do Jornal “O SÃO GONÇALO” - Ano: 1963

Fonte: Jornal "O SÃO GONÇALO

A reportagem acima foi publicada, tendo como pauta o não funcionamento do Instituto de Educação no município de São Gonçalo previsto para aquele ano, e o movimento dos/as alunos/as na luta pelo funcionamento do Instituto, conforme texto da referida reportagem, transcrita abaixo:

\section{Curso Normal do Instituto de Educação de São Gonçalo só em 1965}

Não sabemos porque a má sorte persegue as coisas em São Gonçalo. Tudo a que é nosso decorre sempre de esforços malditos, lutas e campanhas das mais duras e difíceis. Não citemos exemplos para não perdermos tempo. Iremos aos fatos.

Criado o Instituto de Educação de São Gonçalo - tarefa ingente do 
deputado Aécio Nanci - aspiração antiga dos gonçalenses. Agora, com surpresa geral, quando os alunos já estão inscritos e matriculados no Curso Normal, surge a declaração que esse Curso só funcionará daqui há dois anos, isto é, em 1965, deliberação do Conselho Estadual de Educação.

Essa medida gerou protesto, como era natural, e grande número de candidatas a Escola Normal está procurando a imprensa pedindo apoio para a sua justa causa. Os jovens estudantes estiveram na redação do "O SÃO GONÇALO” - diário e disseram de seus propósitos e que haveriam de lutar pelo funcionamento este ano da Escola Normal do Instituto de São Gonçalo, seguindo exemplos através de Teresopólis, Petropólis e muitas cidades para as quais foram criados estabelecimentos idênticos.

As reclamantes posaram para a objetiva de Cezar de Mattos, reportagem que publicaremos oportunamente. (Reportagem da primeira página do "O SÃO GONÇALO” publicada em 19 de janeiro de 1963).

De acordo com o texto acima, foram realizadas as matrículas para o Curso Normal no Instituto de Educação em São Gonçalo. Tal medida deve ter gerado expectativa em relação ao início do curso. No entanto, após uma deliberação do Conselho Estadual de Educação, o início das aulas, previsto inicialmente para o ano de 1963, foi adiado.

Que motivos teria o Conselho Estadual de Educação para adiar o início das aulas do Curso Normal, se o Instituto de Educação já havia sido criado e as matrículas realizadas?

A previsão para o funcionamento do recém-criado Instituto de Educação gonçalense, segundo deliberação do Conselho Estadual de Educação, seria apenas no ano de 1965. Este fato causou mobilização dos/as alunos/as que se organizaram e foram à redação do Jornal "O SÃO GONÇALO”.

A mobilização popular aponta a educação com uma das bandeiras das lutas populares, o que segundo Nunes (2000) ocorreu entre o Estado Novo e foi sufocado pelo golpe militar de 1964:

No intervalo entre o Estado Novo e o regime militar de 1964 a pressão das populações urbanas, sobretudo das classes médias e operárias, em torno dos líderes políticos populistas obrigava-os a institucionalizar os movimentos reivindicatórios mediante a ação da educação escolarizada, transformando a abertura de ginásios públicos em bandeira de lutas nas câmaras estaduais e municipais (NUNES, 2000, p. 46).

Os movimentos de reivindicação pela expansão da rede pública de Ensino Primário e Secundário, de certa forma, se opunham à expansão da rede privada de ensino. A rede privada muitas vezes era financiada pelo poder público, com a distribuição de bolsas de estudos para alunos sem condições financeiras de arcar com as mensalidades.

Revista Interinstitucional Artes de Educar. Rio de Janeiro, V. 2 N. Especial - pag 312-326 (jun - out 2016): "Vozes da Educação" 


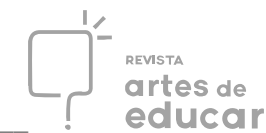

Nunes (2000) aponta que no Estado do Rio de Janeiro "o total de bolsas financiadas se eleva de 7.761 em 1962, para 45.900 bolsas em 1965” (NUNES, 2000, p. 47). Será que a distribuição de bolsas de estudos em escolas particulares gonçalenses teve relação com a decisão do Conselho Estadual de Educação em adiar o início do funcionamento do Instituto de Educação? Teriam os/as alunos/as que se matricularam no Instituto de Educação recebido bolsas de estudo nas escolas particulares de São Gonçalo? Ou desistido de continuar os estudos?

As interrogações que faço são frutos das minhas reflexões realizadas no decorrer da investigação. Lanço-me a formulação de questões instigada pelos achados da pesquisa, como quem tenta "escovar a história a contrapelo" (BENJAMIM, 1996).

As relações entre o poder público e o ensino privado no município de São Gonçalo pareciam se estreitar cada vez mais. No entanto, a luta pelo funcionamento do primeiro Instituto de Educação continuou nas vozes dos/as alunos/as já matriculados, conforme reportagem do Jornal “O SÃO GONÇALO”:

\section{Pelo funcionamento da Escola Normal do I E de São Gonçalo Vitorioso "O SÃO GONÇALO"}

Com prejuizo das candidatas a Escola Normal do novo Instituto de Educação desta cidade, havia se deliberado que a mesma não funcionasse no periodo letivo do corrente ano. Um grupo de jovens estudantes veio à este jornal (foto abaixo) protestando e apelando para o seu funcionamento. O CEE autorizou o funcionamento da Escola Normal no Nilo Peçanha, noticia essa que foi muito bem recebida (Reportagem da primeira página do "O SÃO GONÇALO" publicada em 02 de março de 1963).

O Conselho Estadual de Educação, conforme reportagem acima, autorizou o funcionamento do Curso Normal no Grupo Escolar Nilo Peçanha, uma das mais antigas escolas do município de São Gonçalo, criado no ano de 1917. Uma das minhas hipóteses é que a autorização ocorreu devido aos protestos dos/as alunos/as matriculados/as e suas famílias, já que para continuarem seus estudos na rede pública eles deveriam deslocar-se para o município de Niterói, ou matricular-se em uma das escolas particulares gonçalenses.

Segundo a reportagem, a notícia do início do curso foi "muito bem recebida". Mas, o que teria levado a cessão das salas de aula do Grupo Escolar Nilo Peçanha? Teria sido a pressão dos/as alunos/as junto aos políticos locais?

Acredito que as pressões populares, aliadas aos interesses eleitoreiros, favoreceram as negociações dos políticos locais com os representantes da Secretaria e do Conselho Estadual de 
Educação, possibilitando o funcionamento, ainda que precário do Instituto de Educação gonçalense.

A promessa do Jornal "O SÃO GONÇALO” de acompanhar a luta dos/as alunos/as matriculados/as no Instituto de Educação, ao que tudo indica, foi cumprida. Trago abaixo a publicação datada de 02 de março de 1963, sobre o tema:

Fotografia 3 - Reportagem em prol da Escola Normal em São Gonçalo

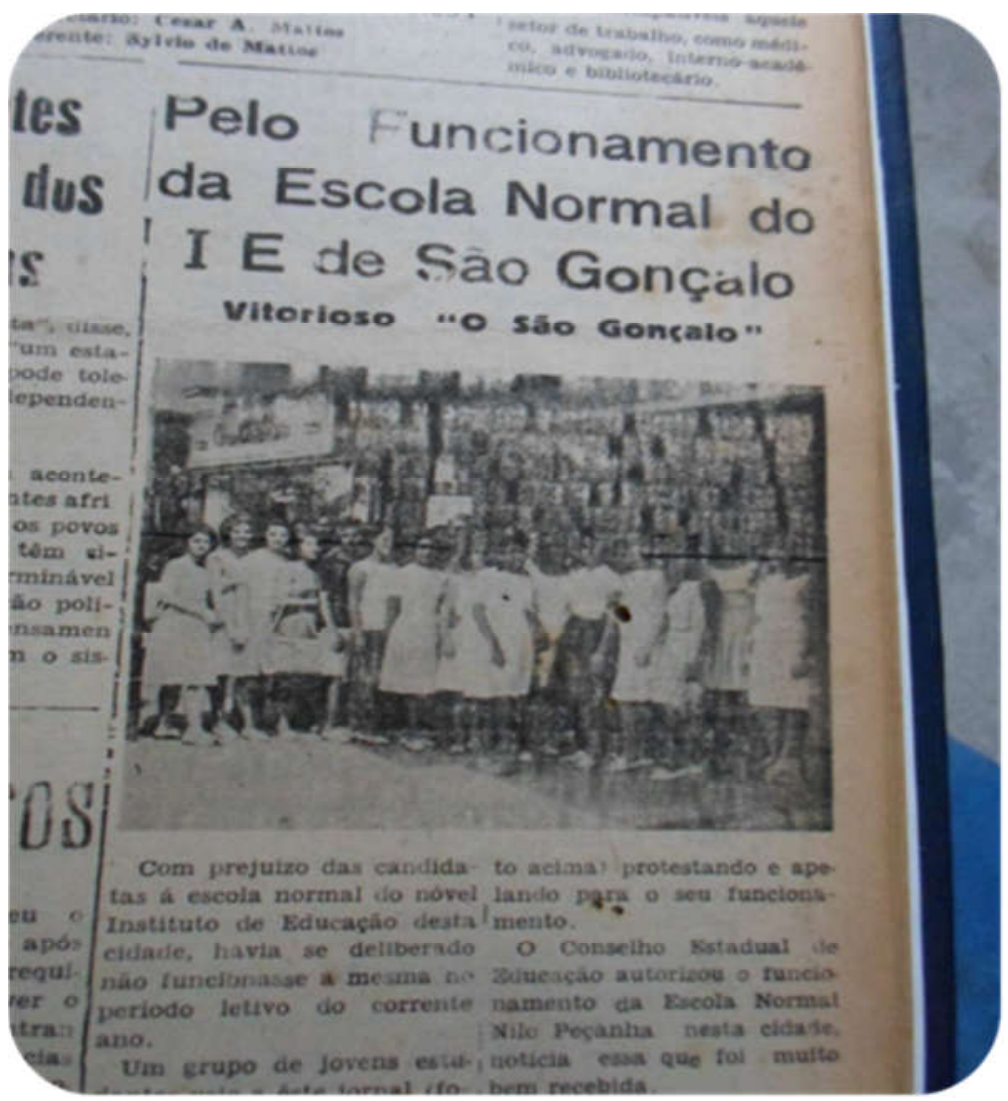

Legenda: Reportagem do Jornal “O SÃO GONÇALO” - Ano: 1963

Fonte: Jornal "O SÃO GONÇALO

No subtítulo da reportagem, o município de São Gonçalo foi tido como "vitorioso", pois foi autorizado o funcionamento do Curso Normal nas dependências do Grupo Escolar Nilo Peçanha.

No entanto, trago algumas questões sobre esta decisão: teria o prédio do Grupo Escolar condições físicas para o funcionamento do Curso Normal? Ou teria sido uma manobra política tendo em vista a mobilização popular?

Estas questões permeiam a história e memória da educação gonçalense, e no caminhar desta investigação insistiram em sair “das zonas de sombra disputando espaço com a história 
oficial" (TAVARES, 2007, p. 29).

Uma questão parecia ser clara, tanto para o povo gonçalense, quanto para os políticos locais: o Instituto de Educação havia sido criado e deveria iniciar seu funcionamento. Foi isto que a última reportagem sobre o assunto, publicada no ano de 1963, afirmava:

Fotografia 4 - Reportagem funcionamento do Instituto de Educação de São Gonçalo

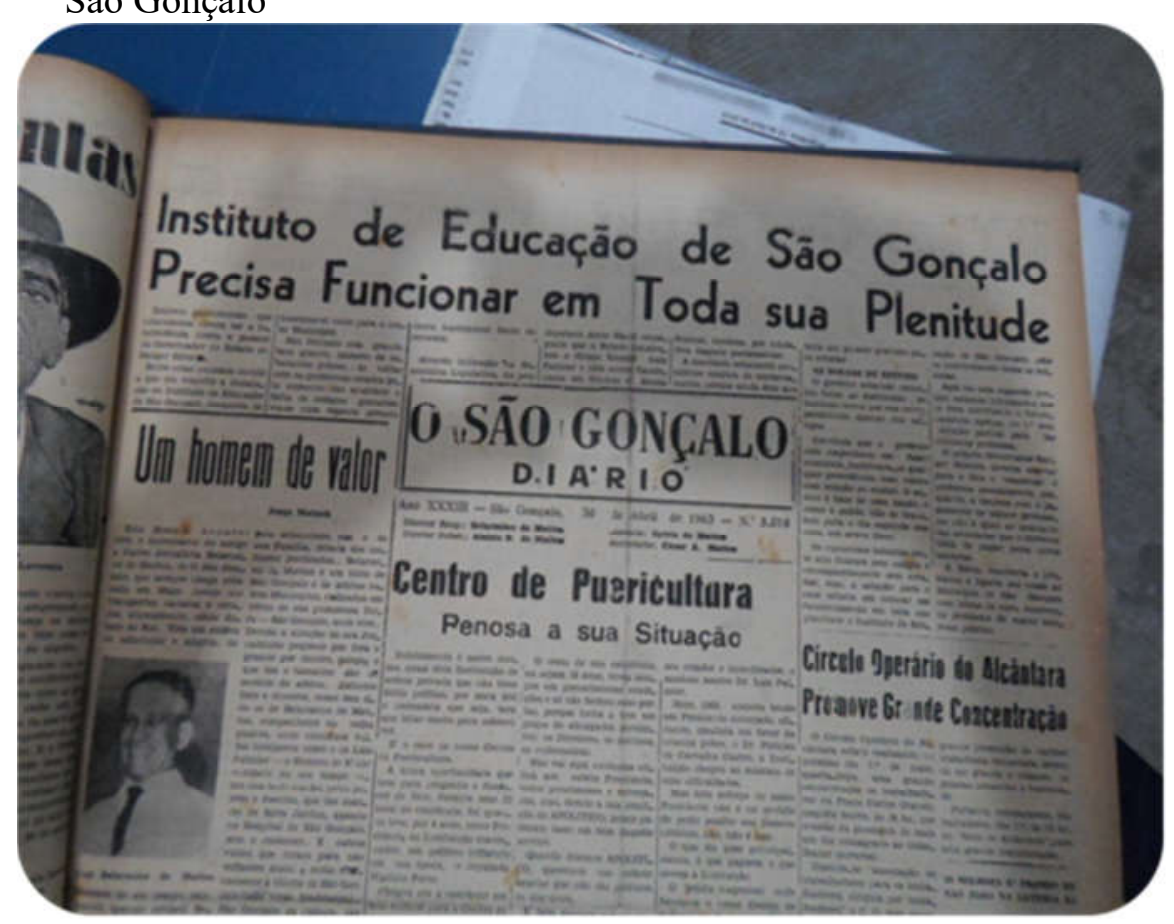

Legenda: Reportagem do Jornal “O SÃO GONÇALO” - Ano: 1963

Fonte: Jornal "O SÃO GONÇALO

O texto da matéria versa sobre a interferência política, o valor da criação do Instituto de Educação, o grande número de alunos/as gonçalenses aguardando o funcionamento da instituição, a necessidade da expansão das escolas públicas, a necessidade da construção de novos Grupos Escolares e o número de alunos/as fora da escola, conforme transcrevo abaixo:

\section{Instituto de Educação de São Gonçalo Precisa Funcionar em Toda sua Plenitude}

Existem providências que entendemos devem ter a interferência direta e pessoal do Governador do Estado Sr. Badger Silveira. Entre elas podemos incluir o que diz respeito a instalação do Instituto de Educação de São Gonçalo, conquista de inestimável valor para o nosso município. São Gonçalo, com grande, bem grande número de estudantes pobres, às voltas com os problemas criados pelo aumento das anuidades e falta de 
colégios gratuitos.

Através da indicação na Assembleia Legislativa, foi pelo deputado Aécio Nanci conseguido que o Estado construísse o Grupo Escolar Luiz Palmier e nele anexo funcionasse o ginásio e a escola Normal. Os numerosos bolsistas deste ano ficaram sem colégio e consequentemente sem estudar, mas a solução para o caso estaria em colocar em funcionamento em toda sua plenitude o Instituto de Educação (Reportagem da primeira página do Jornal "O SÃO GONÇALO" publicada em 30 de abril de 1963).

A necessidade do pleno funcionamento do Instituto de Educação no município de São Gonçalo parecia incontestável. No entanto, foi a partir do ano de 1965, que o Curso Normal foi ofertado no município, em espaço anexo ao Grupo Escolar Luiz Palmier, localizado no bairro Brasilândia.

A pequena nota publicada em 05 de dezembro de 1965 registra o funcionamento "precário" do Instituto de Educação:

Fotografia 5 - Funcionamento precário do Instituto de Educação

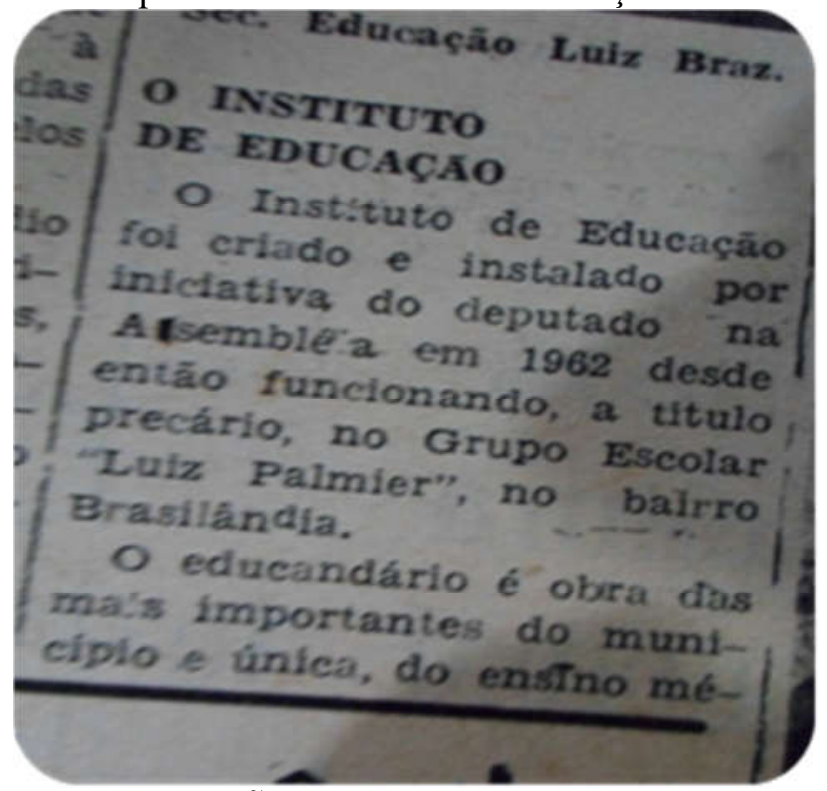

Legenda: Reportagem do Jornal “O SÃ O GONÇALO” - Ano: 1965

Fonte: Jornal "O SÃO GONÇALO

A criação do Instituto de Educação no ano de 1961, a autorização de funcionamento do Curso Normal no período de 1963 a 1965 nas instalações do Grupo Escolar Nilo Peçanha, a transferência a título precário do Curso Normal para o anexo do Grupo Escolar Luiz Palmier, de certa forma, demonstraram as contradições e incoerências acerca da formação de professores no município. 
Estariam estes fatos isolados das políticas educacionais nacionais no regime militar? Seriam, estes, vestígios do projeto educacional dos "Anos de Chumbo"?

De acordo com Sally (2006), as mudanças continuaram acontecendo no que tange ao funcionamento do Instituto de Educação gonçalense, causadas pela influência de políticos locais na gestão do Instituto:

A escola contou com a influência dos políticos, que indicavam professores e diretores para os cargos, numa demonstração evidente do laço estreito de influencias. Por conta desta proximidade, atendendo à solicitação do deputado estadual Amilton Xavier, foi sugerida a alteração do nome da instituição que, com pouco tempo de funcionamento, passou a se chamar Instituto de Educação Clélia Nanci (IECN), através da Lei 5.756, em 17 de agosto de 1966 (SALLY, 2006, p. 63).

A influência política foi um marco na história gonçalense, tal como em âmbito nacional. Os anos da ditadura não conseguiram apagar esta característica tão presente da história política brasileira e, ao que tudo indica, reafirmou-a ainda mais.

A criação, funcionamento e construção do prédio do Instituto de Educação, por quase seis anos foi objeto de disputas políticas e eleitoreiras.

Sua denominação como Instituto de Educação Clélia Nanci (IECN) teve como motivação o fato da Sra. "Clélia Nanci ter sido mãe de um influente político da região" (SALLY, 2006, p. 43).

No entanto, mesmo sem ter vínculo direto com a educação, a Sra. Clélia Nanci formou todos os seus filhos, e "tinha o sonho de que São Gonçalo tivesse uma escola que preparasse os jovens da classe popular para atuar no mercado de trabalho" (BRAGANÇA, 2014, p.135).

A reportagem publicada em abril de 1966 aponta para o posicionamento do Governador do Estado do Rio de Janeiro em relação à construção do prédio do IECN, como sendo de máxima urgência: 
Fotografia 6 - Novo prédio do Instituto de Educação de São Gonçalo

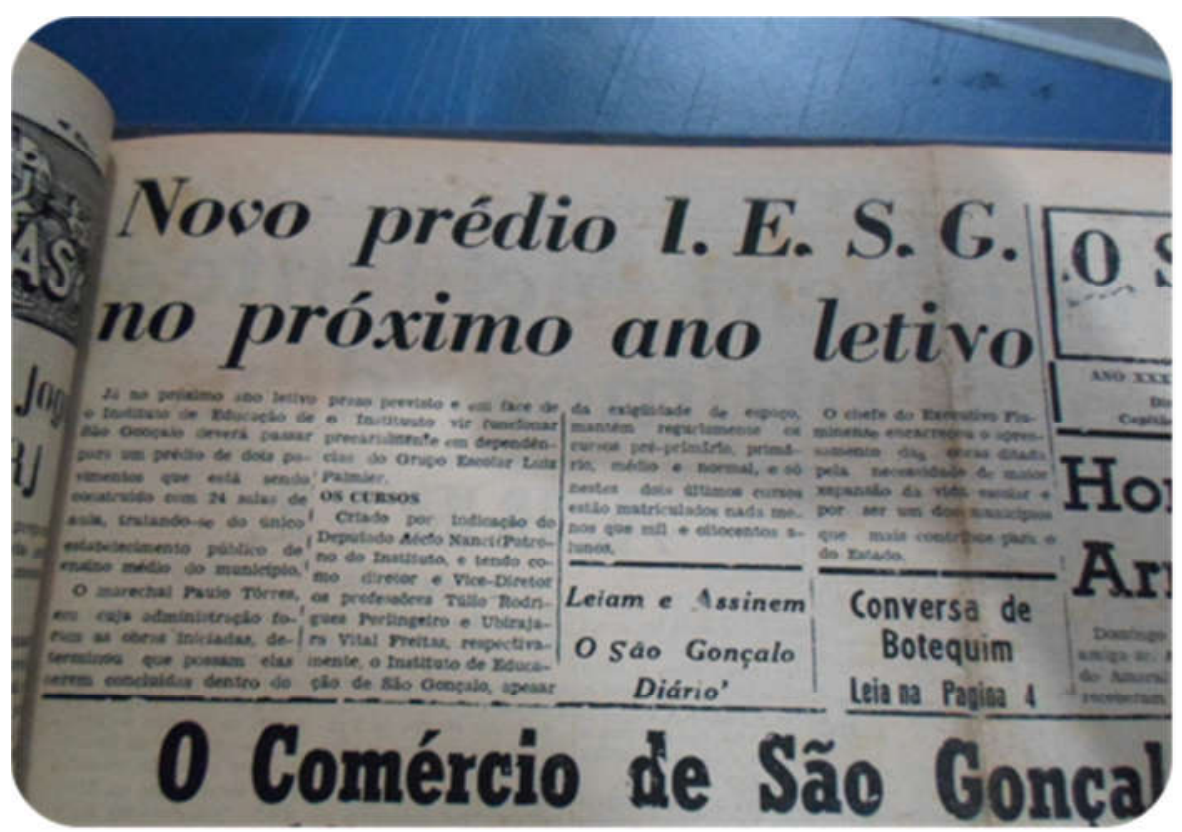

Legenda: Reportagem do Jornal “O SÃO GONÇALO” - Ano: 1966

Fonte: Jornal "O SÃO GONÇALO

A reportagem revela a construção do prédio para o Instituto de Educação de São Gonçalo que, em pleno regime militar, teve na figura do Marechal Paulo Torres a promessa de que as obras seriam concluídas dentro do prazo previsto, conforme abaixo:

\section{Novo prédio do I.E.S.G no próximo ano letivo}

Já no próximo ano letivo o IESG deverá passar para um prédio de dois pavimentos que está sendo construído com 24 salas de aula, tratando-se do único estabelecimento público de ensino médio do município. $\mathrm{O}$ marechal Paulo Torres, em cuja administração foram as obras iniciadas, determinou que possam elas serem concluídas dentro do prazo previsto e em face de o Instituto vir funcionar precariamente em dependências do Grupo Escolar Luiz Palmier. Mantém regularmente os Cursos Préprimário, Primário, Médio e Normal, e só nestes dois últimos cursos estão matriculados nada menos que mil e oitocentos alunos.

$\mathrm{O}$ chefe do Executivo Fluminense esclareceu que o apressamento das obras, são ditadas pela expansão da vida escolar e por ser um dos municípios que mais contribuem para o crescimento do Estado.

(Reportagem da primeira página do Jornal "O SÃO GONÇALO" publicada em 21 de abril de 1966).

$\mathrm{Na}$ reportagem, o término da obra é garantido e necessário, tendo em vista o crescimento 
da procura dos alunos e a importância do município de São Gonçalo na economia fluminense.

No entanto, apenas no ano de 1968 as obras foram concluídas, e o Instituto de Educação Clélia Nanci incorporou-se ao espaço físico do Grupo Escolar Luiz Palmier, tendo sido construído também o Jardim de Infância Ismael Branco.

Com sua estrutura ampliada, estava completo o conjunto que abrigaria os três prédios referentes ao "Curso Normal, o Ginásio, o Primário e o Pré-escolar, sendo esses dois últimos segmentos fundamentais para a prática dos estágios” (SALLY, 2006, p. 63).

A Formação de Professores no âmbito público no município de São Gonçalo somente se concretizou na década de 60. A expansão inicial desses cursos ocorreu por iniciativa da "esfera privada, concorrendo também para ela, a oferta dos estudos adicionais, motivadas pela Lei 5692/71” (FIGUEIRÊDO, 2004, p. 104).

Foi somente no inicio dos anos 80 que a política educacional estadual resolveu ampliar a oferta de vagas no ensino médio, instituindo:

Cursos de Formação de Professores na maioria das escolas estaduais de ensino fundamental, alguns deles, funcionando precariamente. No final desta década, também foi criado, na rede municipal, um curso de mesma natureza, em escola conceituada na cidade, mas também de ensino fundamental (Ibid, 2004, p. 105).

A criação dos Cursos de Formação de Professores no município de São Gonçalo expandiu-se nas escolas estaduais e em uma escola municipal.

Até o ano de 2016, o Curso Normal é ofertado em quatro escolas estaduais gonçalenses: Instituto de Educação Clélia Nanci, localizada no bairro Brasilândia; Colégio Estadual Pandiá Calógeras, localizado no bairro Alcântara; Colégio Estadual Padre Manuel da Nóbrega, localizado no bairro Brasilândia, e Colégio Estadual Trasilbo Filgueiras, localizado no bairro Jardim Catarina.

Inicialmente, os cursos eram oferecidos no horário diurno e noturno, com três anos de duração, e tendo como campo de estágio as turmas de ensino fundamental da própria instituição escolar.

Figueirêdo (2004) ressalta que as criações dos Cursos de Formação de Professores em escolas estaduais coincidiram com o rebaixamento da atividade "profissional do magistério, e a fraca procura de vagas, nas escolas privadas, motivando assim a extinção destes cursos, nos anos 90, em algumas das tradicionais escolas particulares do município" (FIGUEIRÊDO, 2004, p. $105)$. 
Com vistas ao levantamento da oferta do Curso Normal no Brasil, realizei no ano de 2016 uma busca nos sites das Secretarias Estaduais de Educação das 27 unidades federativas, sendo 26 estados e o Distrito Federal, pois não encontrei nenhuma fonte sistematizada com a informação desejada.

A partir das publicações relacionadas ao calendário de matrículas para o ano letivo de 2015, tal como editais e portarias, computei o seguinte quadro quantitativo:

- 12 Estados Brasileiros oferecem o Curso Normal de Nível Médio: Alagoas, Bahia, Ceará, Maranhão, Mato Grosso do Sul, Minas Gerais, Paraíba, Paraná, Pernambuco, Rio de Janeiro, Rio Grande do Sul e Santa Catarina;

- 14 Estados Brasileiros e o Distrito Federal não oferecem o Curso Normal de Nível Médio: Acre, Amapá, Amazonas, Espírito Santo, Goiás, Mato Grosso, Pará, Piauí, Rio Grande do Norte, Rondônia, Roraima, São Paulo, Sergipe, Tocantins e Brasília.

Neste levantamento, temos a quantidade de Estados Brasileiros que oferecem em suas redes de ensino o Curso Normal de Nível Médio, distribuídos em variadas escolas. Acredito que este dado aponta para a resistência da formação de professores em Nível Médio no Brasil, e para as suas "raízes" fincadas na história da educação nacional.

Como exemplo, Lima e Moreira (2014) lembram-nos a discussão realizada na Conferência Nacional de Educação - CONAE, realizada no ano de 2010, em Brasília, onde foi apresentada a proposta de extinção do Curso Normal. De acordo com as autoras, a proposta não obteve a adesão esperada, "e a discussão culminou com a sua retirada, a partir dos argumentos a favor da ideia de que o curso normal poderia ser mantido como parte de um itinerário formativo mais abrangente" (LIMA; MOREIRA, 2014, p. 73).

De acordo com Alvarenga e Tavares (2014), o Curso Normal de nível médio poderia potencializar a formação de professores, no que tange à atuação de muitos/as professores/as na educação infantil e de jovens e adultos. Seria necessária uma ampla reflexão com os atores que constroem nas diversas instituições formadoras brasileiras e maior aproximação entre Universidade e instituições escolares.

Particularmente, acredito que este seria mais um dos inúmeros desafios vivenciados pelo Curso Normal no Brasil, que em meio há muitos já sofridos, insiste na permanência, haja vista a existência da demanda existente de alunos/as em alguns Estados brasileiros. 
Que sentidos o Curso Normal representa atualmente em nossa sociedade? Em que condições de trabalho atuam os/as professores/as formadores nesta modalidade de ensino? Em que aspectos esta formação favorece ou não a vivência das diferentes dimensões da docência? Que tensões existem nas políticas públicas de formação docente em nível local e nacional? Estas questões se entrelaçam e tecem ao longo da história da educação brasileira as tramas que integram o lócus da formação de professores nacional e local.

\section{REFERÊNCIAS BIBLIOGRÁFICAS}

ALVARENGA, Márcia Soares de; TAVARES, Maria Tereza Goudard. A formação dos professores das infâncias e de jovens e adultos em São Gonçalo: desafios contemporâneos. In: ARAÚJO, Mairce. BRAGANÇA, Inês Ferreira de Souza. Experiências na Formação de Professores: memórias, trajetórias e práticas do Instituto de Educação Clélia Nanci, Rio de Janeiro, Lamparina/FAPERJ, 2014.

BRAGANÇA, Inês Ferreira de Souza. Formação permanente de educadores: memória e narração. In: FIGUEIRÊDO, Haydée da Graça Ferreira de; TAVARES, Maria Tereza Goudard. Por que o local? In: FIGUEIRÊDO, Haydée da Graça Ferreira de (org). Vozes da Educação: 500 anos de Brasil. Rio de Janeiro: UERJ, DEPEXT, 2004.

. Do cofre às narrativas. In: ARAÚJO, Mairce.; BRAGANÇA, Inês. Experiências na Formação de Professores: memórias, trajetórias e práticas do Instituto de Educação Clélia Nanci, Rio de Janeiro, Lamparina/FAPERJ, 2014.

Decreto Lei ${ }^{\circ} 8.530$ de 1946. Lei orgânica do Curso Normal. Brasília, 1946.

FIGUEIRÊDO, Haydée da Graça Ferreira de; TAVARES, Maria Tereza Goudard. Por que o local? In: FIGUEIRÊDO, Haydée da Graça Ferreira de (org). Vozes da Educação: 500 anos de Brasil. Rio de Janeiro: UERJ, DEPEXT, 2004.

. Vozes da Educação. In: NUNES, Clarice. Docência e Pesquisa em Educação na Visão de Haydée Figueiredo. Rio de Janeiro: Litteris, 2010.

. Valorizando o Local: a educação gonçalense no século XIX. In: NUNES, Clarice. Docência e Pesquisa em Educação na Visão de Haydée Figueiredo. Rio de Janeiro: Litteris, 2010. Jornal "O SÃO GONÇALO" - exemplares dos anos 1956 a 1967.

LIMA, Débora Borges; MOREIRA, Láelia Carmelita Portela. Formação de Professores em nível médio: Curso Normal em discussão. In: ARAÚJO, Mairce. BRAGANÇA, Inês Ferreira de Souza. Experiências na Formação de Professores: memórias, trajetórias e práticas do Instituto de Educação Clélia Nanci, Rio de Janeiro, Lamparina/FAPERJ, 2014.

NUNES, Clarice. O "velho" e "bom" ensino secundário: momentos decisivos. Revista Brasileira de Educação. São Paulo: maio/jun/jul/ago, 2000, No 14.

. Docência e Pesquisa em Educação na Visão de Haydée Figueiredo. Rio de Janeiro: Litteris, 2010.

SAlLY, Mônica Alves. A Produção de sentidos do Curso Normal: a poética do espaço do Instituto de Educação Clélia Nanci. Dissertação de Mestrado em Educação, Universidade Federal Fluminense, Niterói, 2006.

TAVARES, Maria Tereza Goudard. Os Pequenos e a Cidade: o papel da escola na construção de uma alfabetização cidadã. 2003. Tese (Doutorado em Educação), Universidade Federal do Rio de Janeiro, Rio de Janeiro, 2003.

Percursos e movimentos: dez anos do Vozes da Educação em São Gonçalo. In: ARAUJO, Mairce (orgs). Vozes da Educação: memórias, histórias e formação de professores. Petropólis: DP et Alii, 2007. 
${ }^{i}$ Mestre em Educação - UERJ/FFP, Professora do Colégio Estadual Trasilbo Filgueiras - Jardim Catarina/SG e Supervisora Educacional na Rede Municipal de Niterói. 